\title{
Prognostically orientated multimodality treatment including surgery for selected patients of small-cell lung cancer patients stages IB to IIIB: long-term results of a phase II trial
}

\author{
W Eberhardt', G Stamatis ${ }^{3}$, M Stuschke ${ }^{2}$, H Wilke', MR Müller ${ }^{1}$, S Kolks', M Flasshove', J Schütte', M Stahl', \\ L Schlenger', V Budach ${ }^{2}$, D Greschuchna ${ }^{3}$, G Stüben ${ }^{2}$, H Teschler ${ }^{3}$, H Sack ${ }^{2}$ and S Seeber ${ }^{1}$
}

Departments of ${ }^{1}$ Internal Medicine (Cancer Research) and ${ }^{2}$ Radiotherapy, West German Cancer Center, University of Essen Medical School; Hufelandstraße 55, 45122 Essen, Germany; ${ }^{3}$ Department of Pneumology and Thoracic Surgery, Ruhrlandklinik, Essen-Heidhausen, Germany

Summary Following mediastinoscopy, a prognostically orientated multimodality approach was chosen in selected small-cell lung cancer (SCLC) patients with hyperfractionated accelerated chemoradiotherapy (Hf-RTx) and definitive surgery (S). Stage IB/IIA patients had four cycles of cisplatin/etoposide (PE) and surgery. Stage IIB/IIIA patients had three cycles PE followed by one cycle concurrent chemoradiation including Hf-RTx and surgery. Most stage IIIB patients were not planned for surgery and had CTx followed by sequential RTx or one cycle concurrent CTx/RTx. Of 46 consecutive patients (stage IB six, IIA two, IIB/IIIA 22, IIIB 16) 43 (94\%) showed an objective response. Twentythree of patients (72\%) planned for inclusion of $S$ were completely resected (R0) (IB 6/6, IIA 2/2, IIB/IIIA 13/22, IIIB 2/2). Overall toxicity was acceptable - one patient died of septicaemia, no perioperative deaths occurred. Median follow-up of patients alive $(n=21)$ is 52 months $(30+-75+)$. Median survival and 5-year survival rate of all patients are 36 months and $46 \%$, in R0 patients 68 months and $63 \%$ (R0-IIB/IIIA/IIIB: not yet reached and 67\%). This multimodality treatment including surgery proved highly effective with $100 \%$ local control and remarkable long-term survival after complete resection, even in locally advanced SCLC stages IIB/IIIA patients.

(C) 1999 Cancer Research Campaign

Keywords: small-cell lung cancer; combined modality; surgery; neoadjuvant

Small-cell lung cancer (SCLC) represents a distinct pathological and clinical entity, accounting for about $15-20 \%$ of all lung cancer cases (Parker et al, 1997). Due to its tendency to disseminate early, systemic combination chemotherapy has been the cornerstone of treatment and, depending on initial disease extent, between 80 and $100 \%$ of patients achieve objective responses (Ihde et al, 1997). In localized - limited - disease (LD-SCLC) patients can be cured and the rate of long-term survivors of $10-15 \%$ after 5 years can be increased to between 15 and $20 \%$ by early inclusion of thoracic irradiation (Pignon et al, 1992; Elias et al, 1997). However, even in modern chemoradiation protocols, most patients experience tumour recurrences both locally in the chest as well as at distant locations - preferably the brain (Arriagada et al, 1992, 1995). Recent strategies to improve outcome have included: (a) application of chemotherapy concurrently with radiation (Takeda et al, 1996); (b) intensification of radiotherapy (hyperfractionated accelerated radiation) (Turrisi et al, 1992); (c) combination of both (a) and (b) with integration of radiation as early as possible; and (d) increase of chemotherapy dose intensities supported by autologous bone marrow or peripheral stem cell transplantation (Elias et al, 1993). However, both strategies - to increase local control by aggressive radiation techniques - as well as an escalation of

Received 2 November 1998

Revised 28 April 1999

Accepted 7 June 1999

Correspondence to: W Eberhardt. E-mail: Wilfried.eberhardt@ uni-essen.de systemic treatment intensity - have been hampered by a high rate of local failures between 30 and 50\% (Gray et al, 1995; Elias et al, 1997; Turrisi et al, 1999). Similar to other solid tumours, surgery may represent the most effective local treatment for dealing with residual disease at the bulky primary tumour, even though we do not know which patient subgroups will eventually profit concerning local control, survival, long-term survival or even cure (Choi et al, 1997). On this background, we started a phase II trial in selected SCLC patients, mostly stages IIB, IIIA and IIIB surgically staged by mediastinoscopy, in whom best results in recent concurrent chemoradiation protocols have been reported with 15-26\% 5-year survival rates (McCracken et al, 1990; Turrisi et al, 1999). Aim of the study was to evaluate feasibility, toxicity and efficacy of a prognostically orientated approach in patients consecutively conferred to our institution. Treatment included upfront cisplatin-based chemotherapy, early concurrent chemoradiation with hyperfractionated accelerated radiotherapy in locally advanced/mediastinal risk stages (IIB/IIIA), as well as definitive surgery, if possible, adding up to an aggressive trimodality treatment for the majority of patients.

\section{PATIENTS AND METHODS}

\section{Patient selection}

Patients with histologically/cytologically proven SCLC were eligible. Following mediastinoscopy patients with SCLC stages IB-IIIB were taken onto this trial (Mountain et al, 1997). No 


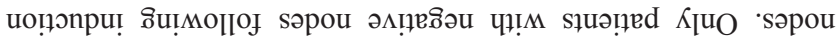

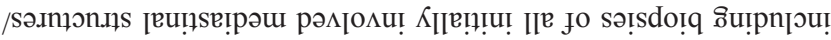

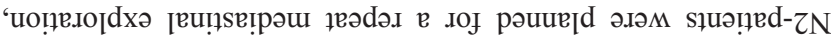

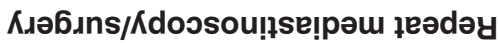

$\kappa \operatorname{son}$

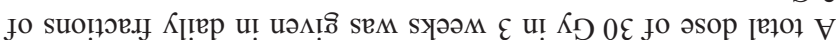

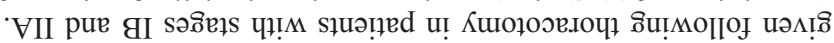

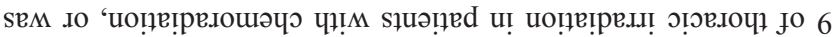

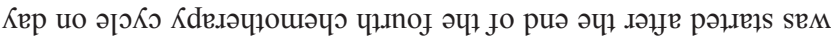

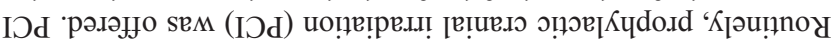

uo!̣е!реג! ןе!иело ग!юе|Кцdoגd

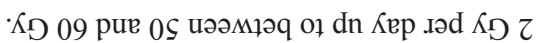

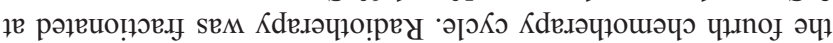

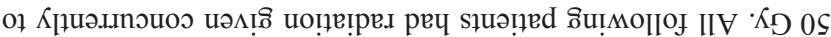

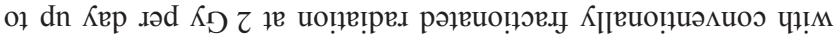

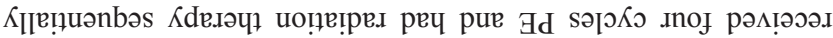

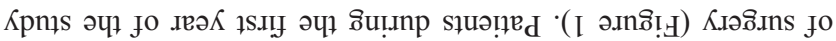

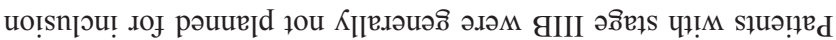

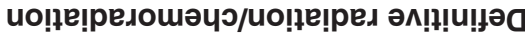

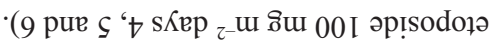

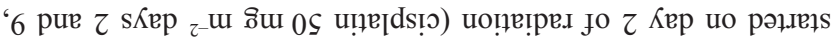

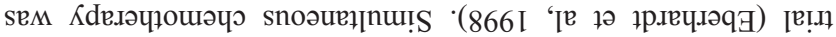

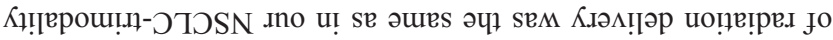

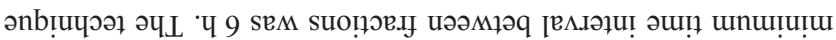

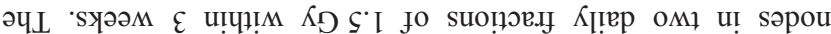

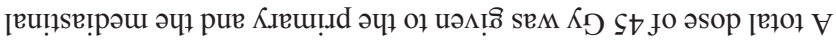

\section{К}

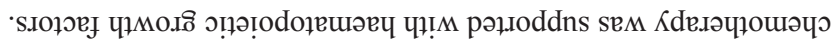

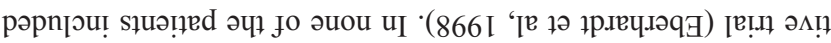

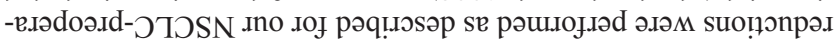

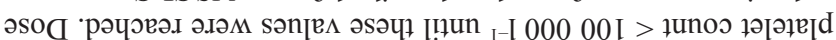

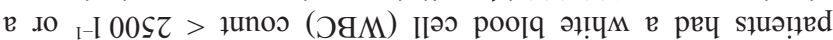

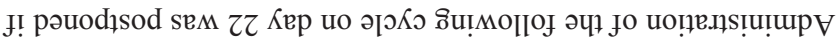

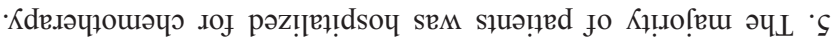

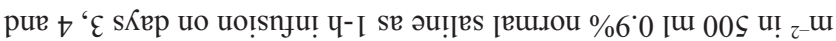

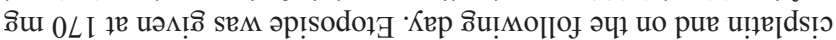

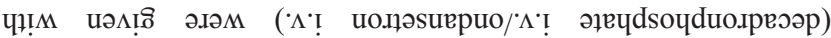

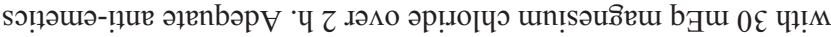

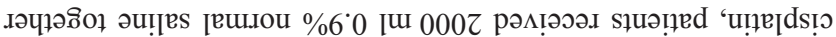

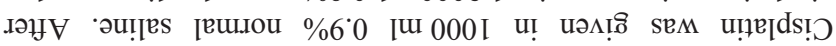

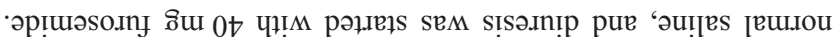

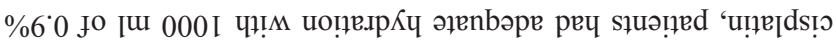

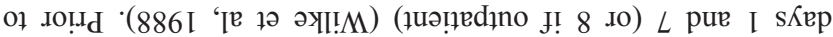

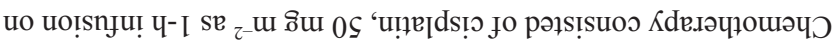

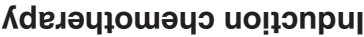

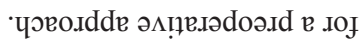

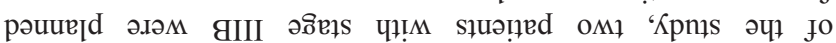
IвәК ұse

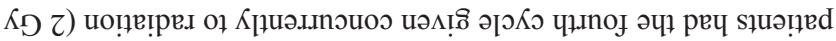

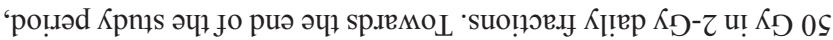

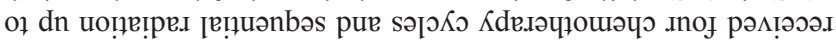

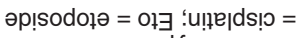

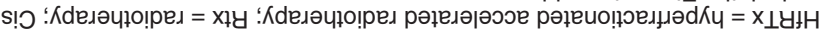

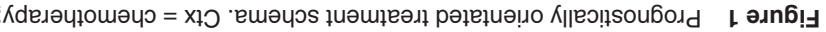

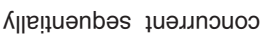
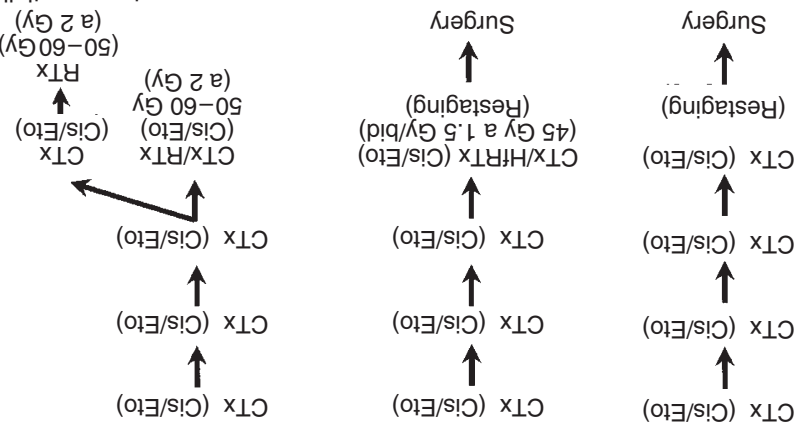

(pəuuejd tou Kıə6ıns) gIII әбеis

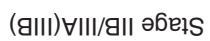

$\forall I I /$ gl ә6еis

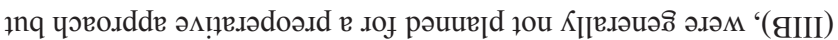

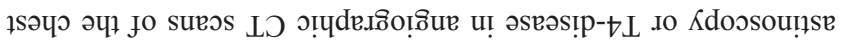
-!рәш ұе әsеәs!̣-

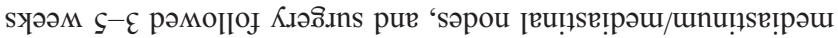

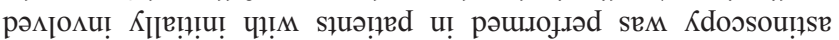

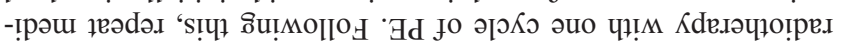

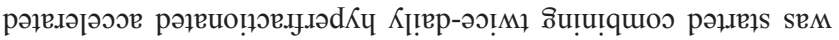

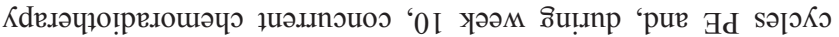

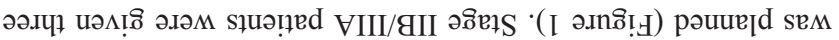

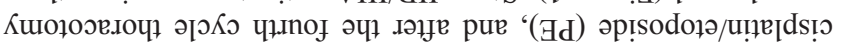

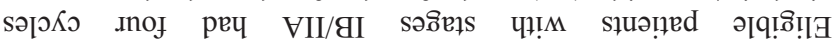

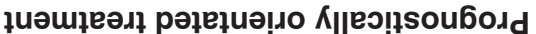

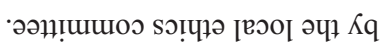

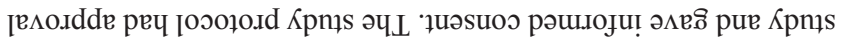

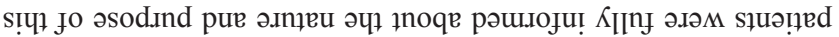

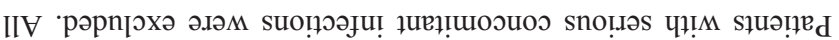

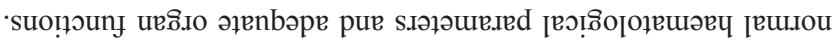

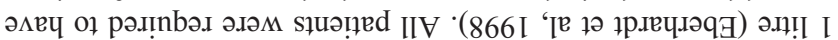

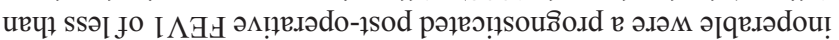

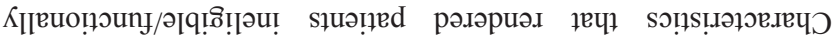
•(866 ' ' [е ұә эрльецләq

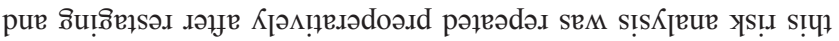

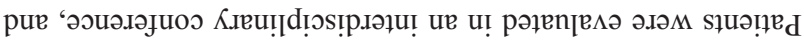

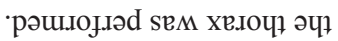

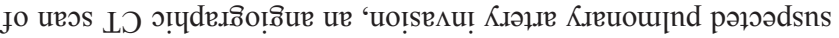

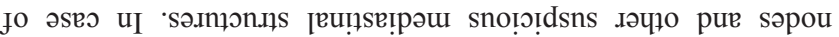

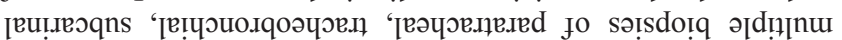

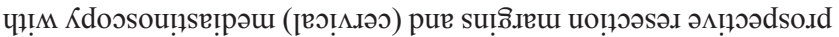

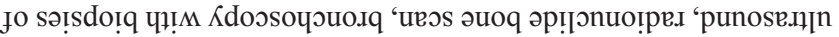

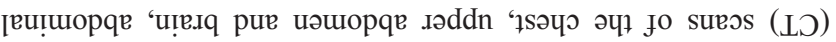

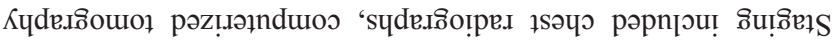

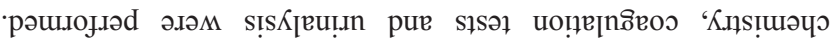

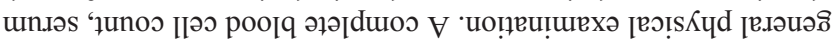

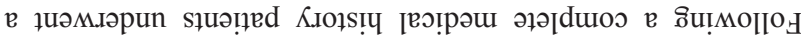

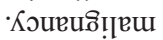

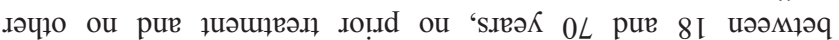

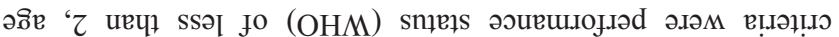

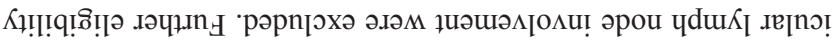

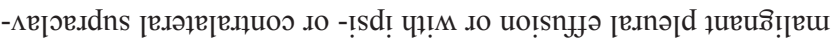

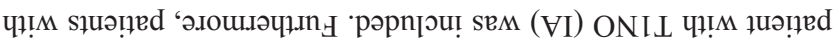




\begin{tabular}{|c|c|c|}
\hline Characteristic & No. & $\%$ \\
\hline All patients & 46 & 100 \\
\hline \multicolumn{3}{|l|}{ Stage } \\
\hline IB T2NO & 6 & 13 \\
\hline IIA T2N1 & 2 & 4 \\
\hline IIB T3NO & 4 & 9 \\
\hline IIIA & 18 & 39 \\
\hline T3N1 & 2 & \\
\hline T2N2 & 10 & \\
\hline T3N2 & 6 & \\
\hline IIIB & 16 & 35 \\
\hline T4N0/N1 & 3 & \\
\hline T4N2 & 3 & \\
\hline T2N3 & 3 & \\
\hline T3N3 & 3 & \\
\hline T4N3 & 4 & \\
\hline \multicolumn{3}{|l|}{ Age, years } \\
\hline Median & 55 & \\
\hline Range & $34-69$ & \\
\hline \multicolumn{3}{|l|}{ Sex } \\
\hline Male & 32 & 70 \\
\hline Female & 14 & 30 \\
\hline \multicolumn{3}{|l|}{ Performance status, WHO } \\
\hline Median & 0 & \\
\hline 0 & 35 & 76 \\
\hline 1 & 11 & 24 \\
\hline \multicolumn{3}{|l|}{ Histological cell type } \\
\hline Small-cell carcinoma & 43 & 94 \\
\hline Mixed small-cell/large-cell & 3 & 6 \\
\hline Lactate dehydrogenase Median (U/I) & 213 & \\
\hline Range (U/I) & 110-393 & \\
\hline
\end{tabular}

proceeded to surgery, whereas boost irradiation up to $60 \mathrm{~Gy}$ was offered to patients with persistent mediastinal disease. Three to 5 weeks after end of irradiation, surgery was planned. Surgical procedures included lobectomies, bilobectomies, sleeve resections, chest wall resections or pneumonectomies as indicated. Because our NSCLC study had shown an increased incidence of stump insufficiencies, bronchial anastomoses were routinely protected with a flap of intercostal muscle in situations considered with an increased risk.

\section{Response and toxicity evaluation}

Responses were assessed using standard WHO criteria (Miller et al, 1981). After surgery, patients were staged using UICC criteria. Toxicities were assessed using the WHO criteria, the RTOG acute radiation toxicity criteria and the RTOG/European Organization for Research and Treatment of Cancer (EORTC) late radiation toxicity criteria (Miller et al, 1981).

\section{Statistics}

Survival was measured from first day of chemotherapy until death, loss to follow-up or time of evaluation for this report. Event-free survival was calculated from first day of chemotherapy until any event occurring such as tumour progression, incidence of second cancer, death due to toxicity, secondary conditions or second malignancy (Green et al, 1994). Survival curves were estimated by the method of Kaplan and Meier (1958). Differences in curves between groups of patients were evaluated using a log-rank test (Mantel et al, 1966).

\section{RESULTS}

\section{Patient characteristics}

Forty-six consecutive SCLC patients were enrolled at our institution from June 1991 until July 1995 and all are eligible for this report. Patient characteristics are given in Table 1. The four stage IIB patients had large centrally located bulky T3N0-tumours with invasion of the mediastinal/pericardial pleura. There were 19 patients with positive N2- and ten with N3-lymph nodes, adding up to 29 of 46 patients $(63 \%)$ with proven mediastinal node disease. Among the patients with IIIB-disease, ten had T4-disease, six pulmonary artery invasion and four diffuse mediastinal organ infiltration.

\section{Induction chemotherapy}

All 46 patients received at least one chemotherapy cycle. One patient died during the first cycle due to septicaemia and was not evaluable for response. One patient with a cerebral infarction during the first cycle and one patient with an infection after the second cycle had to be taken off study. All remaining 43 patients received at least three cycles. Altogether, 134 chemotherapy cycles have been applicated and only in 16 cycles treatment had to be postponed for less than 1 week with dose reduction in ten cycles. All eight patients with stage IB/IIA had the four planned cycles and thoracotomy performed.

\section{Induction chemoradiotherapy}

All 22 patients with stage IIB/IIIA and two further patients with stage IIIB were planned for a preoperative chemoradiotherapy induction. Five patients, one due to decline in performance status and four due to medical reasons, did not proceed to thoracotomy. Two further patients refused surgery and received boost irradiation up to $60 \mathrm{~Gy}$. Thus, of overall 24 patients initially planned to receive the complete preoperative chemoradiation block, this could be delivered in 22 . No interruptions in radiation delivery had to be made.

\section{Definitive chemoradiotherapy}

Of 16 patients with stage IIIB, 14 were initially not planned for inclusion of surgery. In the first year of the study, four were treated with four cycles PE and received sequential radiation up to $50 \mathrm{~Gy}$. Nine of the ten following patients were given concurrrent chemoradiation with one cycle simultaneously to radiation (50-60 Gy).

\section{Maximum clinical response}

The maximum clinical response to induction was evaluable in 45 patients. Sixteen clinical complete responses (CR) (35\%) and 27 partial remissions (PR) (59\%) were achieved, adding up to 43 objective responses (94\%). Stable disease (NC) was found in two patients $(4 \%)$. No patient showed early progression. Most patients had continuously shrinking tumours after each cycle with maximum response following the second cycle and ten patients with further major improvement to chemoradiotherapy (seven PR converted to CR, three NC converted to PR). There were no significant differences in response rates and rates of stable disease between TNM-subgroups or disease stages. 
Table 2 Eligibility for thoracotomy and surgical outcome

\begin{tabular}{lrc}
\hline Patient group & No. & $\%$ \\
\hline All patients & 46 & \\
Not planned for surgery (IIIB, CTx+RTx or CTx/RTx) & 14 & \\
Planned for surgery (stages IB-IIIB) & 32 & 100 \\
Not operable (medical, refusal) & 8 & \\
Operable & 24 & $24 / 3275 \%$ \\
Completely resected (R0) & 23 & $23 / 3272 \%$ \\
Resection of vital tumour tissue & 12 & $12 / 3238 \%$ \\
$\quad$ Macroscopic tumour & 7 & \\
Microscopic tumour & 5 & \\
Small-cell histology & 9 & \\
$\quad$ Non-small-cell histology & 3 & \\
Pathological complete response (pCR) & 11 & $11 / 3234 \%$ \\
& & \\
\hline
\end{tabular}

\section{Eligibility for thoracotomy and surgical outcome}

Thirty-two patients - all of stages IB-IIIA and two of stage IIIB were planned for inclusion of surgery. In 16 patients with involved mediastinal nodes, repeat mediastinoscopy was performed before consideration of surgery (14 in stage IIIA and two in IIIB). In three patients with stage IIIA, positive N2-nodes were found and surgery was no longer found appropriate. Thus, 13 of 16 patients (81\%) with initially positive mediastinal nodes had an $\mathrm{N} 0$-status after the induction. No patient with N0 at repeat mediastinoscopy had microscopic N2-status in his final pathology. At the end of induction chemotherapy \pm chemoradiation, 24 of the planned 32 patients $(75 \%)$ could be operated on (Table 2). One patient turned out irresectable with multiple pleural metastases. In all remaining $23(72 \%$ of patients planned for surgery) the primary tumour could be completely resected. Surgical procedures were: ten pneumonectomies, two bilobectomies and 11 lobectomies. Of these 23 completely resected patients, $12(52 \%)$ had viable tumour tissue (five with microscopic, seven with macroscopic tumour). Histological examinations revealed nine patients with vital pure small-cell carcinoma and three with nonsmall-cell pathology - two with squamous cell and one with largecell anaplastic carcinoma. 11 patients $(34 \%$ of those eligible for surgery) had no vital tumour in resected specimens (pathological complete response - pCR) (Table 2).

\section{Toxicities}

Maximum toxicity in all 46 patients during induction is listed in Table 3. Grade 4 haematologic toxicity occurred in $12(26 \%)$. Severe oesophagitis (grade 3 ) occurred in five patients, but was usually of short duration ( $<10$ days). Three required intravenous hydration with grade 4 oesophagitis, but radiation was not interrupted and oesophagitis completely recovered within 1 week. No oesophageal stricture was observed. One patient died due to septicaemia during the first chemotherapy cycle. Additional grade 3 toxicities were hearing loss (one patient), peripheral neuropathy (one patient) and renal impairment (one patient). No peri- or postoperative deaths occurred. No stump insufficiency or pleural empyema was observed. Four patients received platelet transfusions due to serious thrombocytopenia, six patients received erythrocyte transfusions due to symptomatic anaemia and three had to be taken on antibiotics for fever and infection. Pneumonitis of grade 3 was seen in two patients. To summarize, only one patient $(2 \%)$ died from causes that could be directly attributed to this intensive multimodality treatment.
Table 3 Maximum toxicity during chemotherapy \pm chemoradiotherapy

\begin{tabular}{lrrrrr}
\hline & \multicolumn{5}{c}{ WHO grade $(\boldsymbol{n}=\mathbf{4 6})$} \\
\cline { 2 - 6 } Toxicity & $\mathbf{1}$ & $\mathbf{2}$ & $\mathbf{3}$ & $\mathbf{4}$ & $\mathbf{5}$ \\
\hline Haematological & & & & & \\
$\quad$ Leukocytopenia & 6 & 11 & 22 & 6 & 0 \\
$\quad$ Thrombocytopenia & 6 & 16 & 10 & 5 & 0 \\
$\quad$ Anaemia & 11 & 24 & 8 & 1 & 0 \\
Non-haematological & & & & & \\
Fever/infection & 4 & 5 & 3 & 0 & 1 \\
$\quad$ Nausea and vomiting & 12 & 27 & 3 & 0 & 0 \\
$\quad$ Neurological & 39 & 5 & 1 & 0 & 0 \\
$\quad$ Oesophagus & 17 & 14 & 5 & 3 & 0 \\
Lung & 19 & 9 & 2 & 0 & 0 \\
$\quad$ Heart & 8 & 2 & 1 & 0 & 0 \\
$\quad$ Ototoxicity & 1 & 0 & 1 & 0 & 0 \\
$\quad$ Renal & 12 & 2 & 1 & 0 & 0 \\
$\quad$ Other & 12 & 6 & 0 & 0 & 0 \\
Worst effect reported per patient & 2 & 12 & 23 & 8 & 1 \\
& & & & & \\
\hline
\end{tabular}

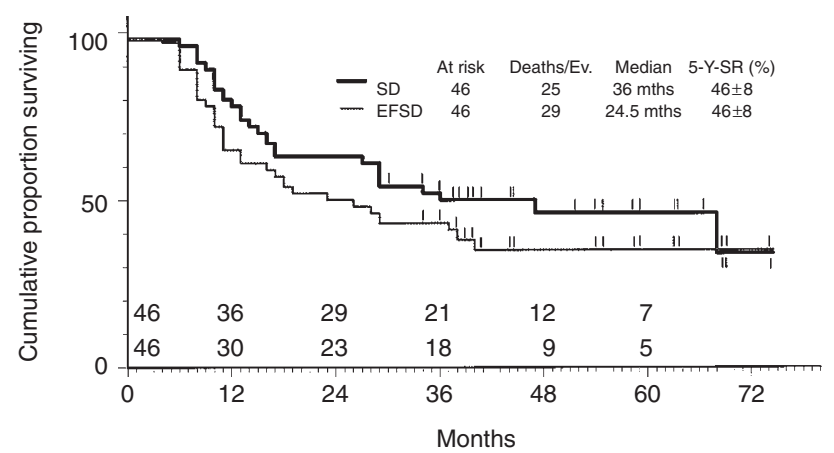

Figure 2 Survival durations (SD) and event-free survival durations (EFSD) in all patients. $S D=$ survival duration; $E F S D=$ event-free survival duration; mths $=$ months; 5 -Y-SR $=5$-year survival rate

\section{Survival}

The median follow-up for all patients was 53 months and 52 for those alive at the time of this report (assessed 1 December 1997). Median survival for all 46 eligible patients was 36 months and actuarial 5-year survival was $46 \%$ (Figure 2). Median event-free survival was 24.5 months with 5-year event-free survival of $36 \%$. The last events at 37, 38 and 40 months were second respiratory cancers. No SCLC-recurrence was seen after 29 months. Of six patients with stage IB, three remain alive at 54, 63 and 66 months. Of two patients with stage IIA, one is alive at 63 months. In 22 patients with stage IIB/IIIA, median survival has not yet been reached with 5-year survival of 50\% and 11 patients alive from 36 to 75 months. In 16 patients with stage IIIB, median survival was 29 months and 5-year survival 35\%. Six remain alive at 30-69 months. No significant difference in survival has been observed between stages IB/IIA, IIB/IIIA and IIIB. Median event-free survival has been 29 months for stage IIIB, not yet reached in IIA, 33.5 months for IIB/IIIA and 15 months in IIIB (IIB/IIIA versus IIIB: $P=0.13$ ). No differences in survival and event-free survival have been observed between different TNM-categories or subgroups defined by $\mathrm{N}$ - and T-parameters, age, sex and initial LDH-values. CR-patients have a median survival of 28 months (30\% actuarial 5-year survival). Patients with PR have not yet 


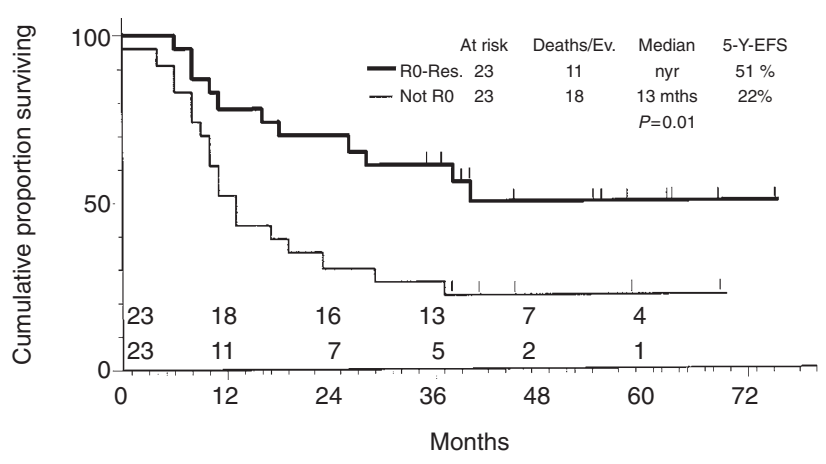

Figure 3 Event-free survival duration in completely resected patients and patients not completely resected - stages IB-IIIB. R0-Res. = R0-(complete) resection; $m$ ths = months; 5 -Y-EFS = 5-year event-free survival; nyr $=$ not yet reached

reached median survival (59\% at 34 months). Of two NC patients one remains alive following $\mathrm{R} 0$-resection at 40 months.

\section{Outcome of patients with complete resection (RO)}

Patients with complete resection (R0) had a median survival of 68 months and a 5-year survival of $63 \%$. Patients in whom complete resection was not part of treatment, had a significantly shorter median survival of 17 months and a 5-year survival of $30 \%$ $(P=0.01)$. Among patients with R0-resection, no differences in long-term survival were found between those with $\mathrm{pCR}$ and those with persistent viable tumour (5-year-survival rate $73 \%$ vs $57 \%$, $P=0.75)$. Actuarial event-free survival has stabilized at $51 \%$ after 5 years for all R0-patients and 58\% after 5 years for R0-patients of stages IIB, IIIA and IIIB (Figures 3 and 4). Of these completely resected patients 12 remain alive and event-free between 34 and 75 months.

\section{Relapse pattern}

Of the 23 R0-patients, nine (36\%) have relapsed. The only site of relapse was distant metastases: eight with isolated central nervous system (CNS) relapse and one with liver metastases. No patient experienced local/locoregional failure. Two patients developed second primaries - one in the contralateral middle lobe and one tracheal carcinoma. Locoregional relapse was seen if complete resection was not part of treatment. Six of 23 patients $(26 \%)$ in this subgroup experienced locoregional failure as first site of relapse, four of these as the only location of failure. Twelve of 23 patients $(52 \%)$ developed distant metastases as first relapse, only in two patients simultaneously to locoregional failure. Again, the brain was the most frequent relapse site, with seven of 23 patients $(30 \%)$ as first site of failure. One patient in this cohort experienced a second primary in the respiratory tract (non-small-cell lung cancer).

\section{DISCUSSION}

The present trial investigated feasibility, toxicity and efficacy of a prognostically orientated multimodality treatment including surgery for selected SCLC-patients. Entered were stages IB-IIIB, without malignant effusions or supraclavicular node involvement,

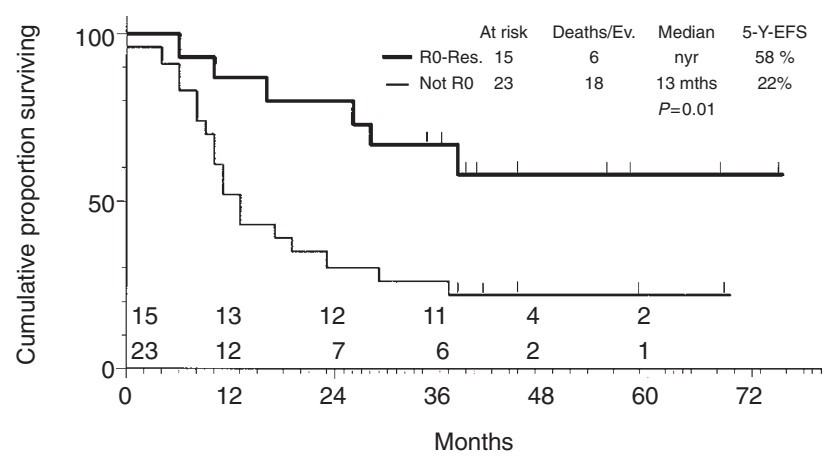

Figure 4 Event-free survival durations in completely resected patients and patients without complete resection - stages IIB/IIIA/IIIB only. R0-Res = R0(complete)resection; $\mathrm{mths}=$ months; $5-\mathrm{Y}-\mathrm{EFS}=$ five-year event-free survival; nyr $=$ not yet reached

although the majority presented with bulky tumours and proven mediastinal disease at staging mediastinoscopy. Our results showed high resectability rates in stages IB-IIIA after chemotherapy plus/minus chemoradiotherapy. No major perioperative morbidity nor any post-operative mortality was observed that may be attributed to a consequent protection of bronchial anastomosis intraoperatively (Eberhardt et al, 1998). With mature longterm follow-up, the median survival for the whole patient cohort of 36 months and an actuarial survival rate of $46 \%$ at 5 years are clearly encouraging.

So far, the best results for SCLC patients have been reported from combined (concurrent) chemoradiation protocols with median survival between 18 and 25 months and 5-year survival of $15-25 \%$, but these were groups with limited disease, not generally excluding positive pleural effusions or involved supraclavicular nodes (McCracken et al, 1990; Turrisi et al, 1992). Twice daily thoracic radiotherapy - included early in the treatment - has been convincingly demonstrated to have an effect on both local control and long-term survival (Turrisi et al, 1999). A different approach intensifies the systemic component (chemotherapeutic doseintensities) supported by autologous bone marrow or peripheral stem cell transplantation (Elias et al, 1997; Fetscher et al, 1997). A small pilot trial in selected patients reported a median survival of 29 months and 5-year survival of $52 \%$, but also observed a remarkably high local-failure rate (Elias et al, 1993). However, high-dose treatment may not be possible in most elderly lung cancer patients and can lead to increased toxicities with mortality rates reported up to $13 \%$ (Fetscher et al, 1997).

A major systemic risk for SCLC patients with prolonged survival duration has turned out to be development of brain metastases. A carefully performed meta-analysis of published randomized trials demonstrated a significant effect of prophylactic cranial irradiation (PCI) on survival in patients with complete response (Arriagada et al, 1998).

In contrast, insufficient local control at bulky tumour areas can be another reason for eventual recurrence. Even after three to four chemotherapy cycles a rate of vital residual disease at the primary site between 55 and $80 \%$ has been found at adjuvant surgery (Shepherd et al, 1996). Interestingly, some of the resected specimens demonstrate a change to NSCLC-histopathologies - whether treatment induced or simply a result of initial tumour cell heterogeneity is still not clear (Shepherd et al, 1988). Some investigators 
have given chemotherapy preoperatively to stages I-IIIA (Shepherd et al, 1989; Zatopek et al, 1991; Müller et al, 1992), others post-operatively (Macchiarini et al, 1989; Ulsperger et al, 1991; Davis et al, 1993). Modern cisplatin-based chemotherapy was rarely used and different policies concerning integration of radiotherapy were chosen. Only one study has given a bimodal induction combining chemotherapy and radiotherapy, but the patient number finally operated on was too small to draw conclusions (Gridelli et al, 1994).

The only randomized trial testing surgery following induction chemotherapy came from the Lung Cancer Study Group (LCSG). After five chemotherapy cycles, responding patients were randomized to receive either chest radiotherapy or surgery followed by radiotherapy (Lad et al, 1994). Preliminary results of this trial did not support the use of surgery in comparable patient subgroups. However, the patient selection of the LCSG-trial was not comparable to the one in our study. The LCSG did not include staging mediastinoscopy, patients were not a priori assessed to be resectable and were randomized only following response to chemotherapy. Moreover, this trial has also been criticized concerning its final conclusions and consequences (Shepherd et al, 1996).

On this background, we reconsidered surgery as definitive local treatment following induction chemotherapy plus/minus concurrent chemoradiotherapy in stages IB-IIIA. Of note is the high rate of $100 \%$ locoregional control following complete resection. Median survival of 68 months and a 5-year survival of $63 \%$ in this subgroup are promising and point to the efficacy of this approach also in patients in stage IIIA (N2). Different to our findings with preoperative chemoradiation, earlier investigations with chemotherapy alone followed by surgery had been disappointing for mediastinal N2-disease (IIIA(N2)) (Meyer et al, 1984; Shepherd et al, 1993).

In conclusion, surgery in SCLC can be considered in stages IB and IIA following chemotherapy, but has also demonstrated to be feasible in stages IIB and IIIA following induction chemoradiotherapy. Its definitive value on local control or long-term prognosis could only be evaluated in a further randomized trial that is urgently needed in this disease with overall poor long-term results and in which the impact of local control may have been underestimated.

\section{ACKNOWLEDGEMENTS}

We express our deepest gratitude to all the nurses, physicians, and others who provided care and support for the patients who participated in this study.

\section{REFERENCES}

Arriagada R, Kramar A, Le Chevalier T and De Cremoux H (1992) Competing events determining relapse-free survival in limited small-cell lung carcinoma. J Clin Oncol 10: 447-451

Arriagada R, Le Chevalier T, Borie F, Rivière A, Chomy P, Monnet I, Tardivon A, Viader F, Tarayre M and Benhamou S (1995) Prophylactic cranial irradiation for patients with small-cell lung cancer in complete remission. J Natl Cancer Inst 87: 183-190

Arriagada R, Auperin A, Pignon JP, Gregor A, Stephens R, Kristjansen PEG, Johnson B, Ueoka H, Wagner H and Whitacre M (1998) Prophylactic cranial irradiation overview in patients with small-cell lung cancer in complete remission. Proc Am Soc Clin Oncol 17: 457 (abstr 1758)

Choi NC, Carey RW, Daly W, Mathisen D, Wain J, Wright C, Lynch T, Grossbard M and Grillo H (1997) Potential impact on survival of improved tumor downstaging and resection rate by preoperative twice-daily radiation and concurrent chemotherapy in stage IIIA non-small-cell lung cancer. J Clin Oncol 15: 712-722

Davis S, Crino L, Tonato M, Darwish S, Pelicci PG and Grignani F (1993) A prospective analysis of chemotherapy following surgical resection of clinical stage I-II small cell lung cancer. Am J Clin Oncol 16: 93-95

Eberhardt W, Wilke H, Stamatis G, Stuschke M, Harstrick A, Menker H, Krause B Müller MR, Stahl M, Flasshove M, Budach V, Greschuchna D, Konietzko N, Sack H and Seeber S (1998) Preoperative chemotherapy followed by concurrent chemoradiation therapy based upon hyperfractionated accelerated radiotherapy and definitive surgery in locally advanced non-small-cell lung cancer: mature results of a phase II trial. J Clin Oncol 16: 622-634

Elias AD, Ayash L, Frei III E, Skarin AT, Hunt M, Wheeler C, Schwartz G, Mazanet R, Tepler I, Eder JP, McCauley M, Herman T, Schnipper L and Antman KH (1993) Intensive combined modality therapy for limited-stage small-cell lung cancer. J Natl Cancer Inst 85: 559-566

Elias AD (1997a) Small cell lung cancer: state-of-the-art therapy in 1996. Chest 112: 251S-258S

Elias AD (1997b) Dose-intensive therapy in lung cancer. Cancer Chemother Pharmacol 40: S64-S69

Fetscher S, Brugger W, Engelhardt R, Kanz L, Hasse J, Frommhold H, Wenger M, Lange W and Mertelsmann R (1997) Dose-intense therapy with etoposide, ifosfamide, cisplatin, and epirubicin (VIP-E) in 100 consecutive patients with limited- and extensive-disease small-cell lung cancer. Ann Oncol 8: 49-56

Gray JR, Sobczak ML, Hahn SM, Sullivan FJ, Johnson BE and Bridges JD (1995) Analysis of local control in 150 limited stage small-cell-lung cancer patients treated with combined thoracic irradiation and multiagent chemotherapy. Proc Am Soc Clin Oncol 14: 349 (abstr 1056)

Green MR, Cox JD, Ardizzoni A, Arriagada R, Bureau G, Darwish S, Deneffe G, Fukuoka M, Joseph D and Komaki R (1994) Endpoints for multimodal clinical trials in stage III non-small cell lung cancer (NSCLC): a consensus report. Lung Cancer 11 Suppl 3: S11-S13

Gridelli C, D'Aprile M, Curcio C, Brancaccio L, Palmeri S, Comella G, Veltri E, Ferrante G, Gentile M and Rossi A (1994) Carboplatin plus epirubicin plus VP16 , concurrent 'split course' radiotherapy, and adjuvant surgery for limited small-cell lung cancer. Lung Cancer 11: 83-91

Ihde DC, Pass HI and Glatstein EJ (1997) Small cell lung cancer. In: Cancer: Principles and Practice of Oncology, 5th edn, DeVita VT Jr, Hellman S and Rosenberg SA (eds), pp. 911-949. Lippincott: Philadelphia

Johnson DH, Kim K, Sause W, Komaki R, Wagner H, Aisner S, Livingston R, Blum $\mathrm{R}$ and Turrisi AT (1996) Cisplatin and etoposide plus thoracic radiotherapy administered once or twice daily in limited stage small cell lung cancer: Final report of Intergroup Trial 0096. Proc Am Soc Clin Oncol 15: 374 (abstr 1113)

Kaplan EL and Meier P (1958) Nonparametric estimation from incomplete observations. J Am Statist Assoc 53: 457-481

Lad T, Piantadosi S, Thomas P, Payne D, Ruckdeschel J and Giaccone G (1994) A prospective randomized trial to determine the benefit of surgical resection of residual disease following response of small-cell lung cancer to combination chemotherapy. Chest 106: 320S-323S

McCracken JD, Janaki LM, Crowley JJ, Taylor SA, Shankir Giri PG, Weiss GB, Gordon W, Baker LH, Mansouri A and Kuebler JP (1990) Concurrent chemotherapy/radiotherapy for limited small-cell lung carcinoma: a Southwest Oncology Group study. J Clin Oncol 8: 892-898

Macchiarini P, Mussi A, Basolo F, Bruno J and Angeletti CA (1989) Optimal treatment for T1-3N0M0 small cell lung cancer: surgery plus adjuvant chemotherapy. Anticancer Res 9: 1623-1625

Mantel N (1966) Evaluation of survival data and two new rank order statistics arising in its consideration. Cancer Chemother Rep 50: 163-170

Meyer JA, Gullo JJ, Ikins PM, Comis RL, Burke WA, Di Fino SM and Parker FB Jr (1984) Adverse prognostic effect of N2 disease in treated small-cell carcinoma of the lung. J Thorac Cardiovasc Surg 88: 495-501

Miller AB, Hoogstraten B, Staquet M and Winkler A (1981) Reporting results of cancer treatment. Cancer 47: 207-214

Mountain CF (1997) Revisions in the international system staging lung cancer. Chest 111: $1710-1717$

Müller LC, Salzer GM, Huber H, Prior C, Ebner I, Frommhold H and Präuer HW (1992) Multimodal therapy of small cell lung cancer in TNM stages I through IIIa. Ann Thorac Surg 54: 493-497

Parker SL, Tong T, Bolden S and Wingo PA (1997) Cancer statistics, 1997. CA Cancer J Clin 47: 5-27

Pignon JP, Arriagada R, Ihde DC, Johnson DH, Perry MC, Souhami RL, Brodin O, Joss RA, Kies MS, Lebeau B, Onoshi T, Osterlind K, Tattersall MHN and Wagner H (1992) A meta-analysis of thoracic radiotherapy for small-cell lung cancer. N Engl J Med 327: 1618-1624 
Shepherd FA, Evans WK, Feld R, Young V, Patterson GA, Ginsberg R and Johansen E (1988) Adjuvant chemotherapy following surgical resection for small-cell carcinoma of the lung. J Clin Oncol 6: 832-838

Shepherd FA, Ginsberg RJ, Patterson GA, Evans WK and Feld R (1989) A prospective study of adjuvant surgical resection after chemotherapy for limited small cell lung cancer. A University of Toronto Lung Oncology Group study. J Thorac Cardiovasc Surg 97: 177-186

Shepherd FA, Ginsberg RJ, Haddad R, Feld R, Sagman U, Evans WK, De Boer G and Maki E (1993) Importance of clinical staging in limited small-cell lung cancer: a valuable system to separate prognostic subgroups. J Clin Oncol 11: $1592-1597$

Shepherd F (1996) Surgical management of small-cell lung cancer. In: Lung Cancer: Principles and Practice. Pass HI, Mitchell JB, Johnson DH and Turrisi AT (eds), pp. 889-913. Lippincott-Raven: Philadelphia

Takada M, Fukuoka M, Furuse K, Ariyoshi Y, Ikegami H, Kurita Y, Nishiwaki Y, Nishiwaki H, Watanabe K, Noda K and Saijo N (1996) Phase III study of concurrent versus sequential thoracic radiotherapy in combination with cisplatin and etoposide for limited-stage small cell lung cancer: Preliminary results of the Japan Clinical Oncology Group. Proc Am Soc Clin Oncol 15: 372 (abstract 1103)
Turrisi AT, Glover DJ, Mason B and Tester W (1992) Long term results of platinum etoposide + twice-daily thoracic radiotherapy for limited small-cell lung cancer: results on 32 patients with 48 months minimum F/U. Proc Am Soc Clin Oncol 11: 292 (abstract 975)

Turrisi AT, Kim K, Blum R, Sause WT, Livingston RB, Komaki R, Wagner H, Aisner S and Johnson DH. Twice-daily compared with once-daily thoracic radiotherapy in limited small-cell lung cancer treated concurrently with cisplatin and etoposide. $N$ Engl J Med 340: 265-271

Ulsperger E, Karrer K and Denck H (1991) Multimodality treatment for small cell lung cancer. Preliminary results of a prospective, multicenter trial. The ISCLung Cancer Study Group. Eur J Cardiothorac Surg 5: 306-310

Wilke H, Achterrath W, Schmoll HJ, Gunzer U, Preusser P and Lenaz L (1988) Etoposide and split-dose cisplatin in small cell lung cancer. Am J Clin Oncol 11: $572-578$

Zatopek NK, Holoye PY, Ellerbroek NA, Hong WK, Roth JA, Ryan MB, Komaki R, Pang AC and Glisson BS (1991) Resectability of small cell lung cancer following induction chemotherapy in patients with limited disease (stage II-IIIb). Am J Clin Oncol 14: 427-432 